\title{
Effective High-Dose Clonazepam Treatment in Two Patients with Opsoclonus and Myoclonus: GABAergic Hypothesis
}

\author{
Aleš Bartoš \\ Charles University Prague, 3rd Faculty of Medicine, Department of Neurology, University Hospital \\ Královské Vinohrady, Prague, Czech Republic
}

\section{Dear Sir,}

It is a challenge to treat opsoclonus or myoclonus. Opsoclonus consists of involuntary, arrhythmic, chaotic, conjugate saccades occurring in all directions. It is usually associated with myoclonus involving the trunk, limbs or head. Opsoclonus and myoclonus are most often found together in the opsoclonus-myoclonus syndrome (OMS). OMS is usually associated with malignancy or occurs as a postinfectious condition. This syndrome is believed to be an immune-mediated self-limiting process, with recovery in the majority of patients with idiopathic or postinfectious OMS. Symptoms and signs subside spontaneously or with drug therapy $[1,2]$. A wide variety of medications exist, of which intravenous immunoglobulins seem to be most effective [3]. Glucocorticoids are not effective in adult-onset OMS [2]. Full or partial remission is typically achieved within several weeks or months. Magnetic resonance (MR) imaging of the brain is usually normal despite severe clinical disability $[1,4]$.

We here refer to our experience with two patients with opsoclonus and myoclonus treated effectively with clonazepam after steroids appeared to be ineffective.

\section{Case Reports}

The clinical picture, appropriate investigations and cytological and humoral dynamics in cerebrospinal fluid (CSF) of both patients have been described in detail elsewhere [5]. Briefly, two consecutive young adults aged 34 and 29 years exhibited repeated vomiting, vertigo, truncal ataxia, opsoclonus and generalized myoclonus. Both deteriorated to the peak of clinical disability 1 month later when they lost the ability to walk and were confined to bed. In both patients, the cellular and humoral CSF alterations were only slight at onset, becoming more pronounced 1 month later. A mononuclear pleocytosis increased within the first month and then normalized during the following weeks. Intrathecally synthesized $\operatorname{IgM}$ occurred only transiently after 1 month of illness, whereas intrathecal IgG production increased during the first month and persisted for up to 8 months. An increasing number of oligoclonal IgG bands during the course of the disease indicated expanding local intrathecal synthesis. Paraneoplastic etiology was ruled out by normal findings of extensive investigations for malignancy and negative paraneoplastic ( $\mathrm{Hu}, \mathrm{Ri}, \mathrm{Yo})$ and anti-glutamate acid decarboxylase (GAD) autoantibodies.

\section{Patient 1}

In the first patient repeated MR imagings of the brain performed at the onset, 1 and 6 months later were normal. Singlephoton emission computed tomography (SPECT) showed reduced perfusion main- ly in the right cerebellar hemisphere and in the white matter of the right frontotemporal region. The patient was initially treated with a total dose $2.25 \mathrm{~g}$ of methylprednisolone for the first week, followed by $60 \mathrm{mg}$ of prednisone daily, tapered over the following 6 weeks. Neurological symptoms worsened despite treatment with steroids and other drugs (maximum dose per day): thiamine (300 $\mathrm{mg})$, piracetam (9,000 mg), acyclovir (750 mg), carbamazepine (1,200 mg), lamotrigine (100 mg), tiapride (900 mg) and clonazepam (4 mg). The abnormal movements started to subside on an increased dose of clonazepam (8 $\mathrm{mg}$ ) from the fifth week. The patient began to recover 1 week before a 5-day attempt with intravenous immunoglobulins at a dose of $0.4 \mathrm{~g} / \mathrm{kg} /$ day started on day 45 after disease onset. He could sit on his bed or watch TV after 2 months and he could walk unaided 1 month later. Throughout the further course of the disease, the patient's status was dependent on the dose of clonazepam: an increase was accompanied with improvement and an attempt to reduce the dose caused worsening of his symptoms. The clonazepam needed to be reduced very slowly over several months. A mild neck myoclonus induced by head anteflexion was the only sequela after clonazepam withdrawal 1 year later.

\section{KARGER}

Fax +4161306 1234 E-Mail karger@karger.ch www.karger.com
C 2006 S. Karger AG, Basel $0014-3022 / 06 / 0564-0240 \$ 23.50 / 0$

Accessible online at: www.karger.com/ene
Aleš Bartoš, MD

Charles University Prague, 3rd Faculty of Medicine, Department of Neurology

University Hospital Královské Vinohrady, Šrobárova 50

CZ-100 34 Prague 10 (Czech Republic)

Tel. +420 267162297 , Fax +420 26716 2377, E-Mail abartos@fnkv.cz 
Patient 2

Initial brain MR imaging of the second patient was normal. SPECT showed hypoperfusion in the right cerebellum and in the right temporal lobe. She received $2.75 \mathrm{~g}$ of methylprednisolon combined with gabapentin (up to $2.4 \mathrm{~g} /$ day) within the first week of the disease, yet her opsoclonus and myoclonus worsened. In the second week the administration of clonazepam $12 \mathrm{mg}$ daily dramatically decreased involuntary ocular and myoclonic jerks and she started walking. Recovery was prolonged and incomplete. Her opsoclonus and myoclonus mirrored the changes in the clonazepam dose. Five years after the initial presentation she still needs to take $5 \mathrm{mg}$ clonazepam daily to control residual mild truncal ataxia. She has partial gaze palsy on the horizontal and vertical planes and a permanently blurred vision for details. She is unable to read. Opsoclonus is present with eyes closed. She has a partial atrophy of the optic discs and a relative afferent pupillary defect in both eyes. Defects in the eye fields have become larger and, with vision only preserved in the periphery, she is almost blind. Visual evoked potentials with artifacts are difficult to reproduce and they are without gross abnormality. Brainstem-evoked potentials are normal. On brain MR imaging there are new punctiform unspecific lesions in the white matter (paraventricular and subcortical distribution, mainly in the frontal lobes).

\section{Discussion}

Brain MR imagings were normal throughout the whole clinical course in the first patient and at the beginning in the second patient, despite a dramatic presentation with severe disability and intensifying CSF signs of inflammation and immune response. Functional alterations or subtle biochemical changes in our patients were beyond resolution of conventional MR imaging. Hypoperfusion on SPECT imaging of the patients' cerebellum is in agreement with observations of functional impairment by others using either SPECT or functional MR imaging [4, 6]. Moreover, we observed hypoperfusion in the cerebral hemisphere, namely in the temporal region. Interestingly, all SPECT defects were seen on the right.

The initial steroid therapy did not improve the neurological deficits. Several drugs proved ineffective, whereas both patients responded well to clonazepam. A spontaneous improvement is also a possible explanation. The prominent resolution of symptoms, however, correlated with increasing doses of clonazepam. The second patient was first treated with steroids and another GABAergic agent. Following treatment failure, clonazepam was introduced during clinical deterioration. It is more likely that the reduction in symptoms and signs was due to medication rather than to a spontaneous recovery, the more so as the patient was still deteriorating when given clonazepam. In both cases, either the effect of clonazepam alone or in combination with a spontaneous recovery ameliorated the patients' symptoms.

High clonazepam doses were necessary (up to $12 \mathrm{mg}$ daily), surprisingly without the usual side-effects. Moreover, the patients' conditions were dose dependent. An attempt to taper clonazepam resulted in worsening of the signs. Complete withdrawal was possible after 1 year in the first patient, the second patient is still on clonazepam, even after 5 years. In the literature clonazepam was shown to be either useful or ineffective [7-9]. The dose was, however, not noted or low in some of these patients. A recent paper corroborates our experience with high-dose clonazepam [10]. The role of intravenous immunoglobulins in the first patient is difficult to determine since this treatment was applied just after the onset of recovery. It may have facilitated recovery.

We hypothesize that altered GABA neurotransmission could be involved in the OMS pathogenesis of our patients. The positive clinical response to clonazepam in our patients suggests GABAergic involvement. Clonazepam enhances GABAergic function by allosteric modulation of $\mathrm{GABA}_{\mathrm{A}}$ receptors. GABAergic neurons responsible for inhibitory processes are found in great abundance in the cerebellum and neocortex. GABA is formed by decarboxylation of glutamate. GABA binds to $\mathrm{GABA}_{\mathrm{A}}$ receptors, the alpha unit of which is modulated with benzodiazepines. Clonazepam potentiates this chloride channel-opening action of GABA on the $\mathrm{GABA}_{\mathrm{A}}$ receptor. GABA is broken down by GABA transaminase, which regenerates glutamate through the formation of succinic semialdehyde. Thus the metabolisms of the principal CNS excitatory and inhibitory neurotransmitters are intimately linked [11]. Reduced GABAergic neurotransmission, prevailing excitatory pathways or impaired balance be- tween the excitatory and inhibitory mediators may result in opsoclonus, myoclonus or truncal ataxia. Decreased GABA neurotransmission may be caused in the presynaptic part by loss of inhibitory neurons, e.g. Purkinje cells, or by impaired synthesis and release of GABA. This view is supported by some histopathological findings that saw a loss of cerebellar Purkinje cells, lesions of the inferior olives or of the lower medulla. The neuropathological features in an idiopathic (viral) case of OMS were very similar to those described in paraneoplastic cerebellar degeneration, despite differences in the phenotype of the two syndromes [2]. The reduced synthesis of GABA may be a consequence of antibodies against GAD, usually occurring in the stiff-person syndrome. Anti-GAD antibodies were not present in our patients. Failure of GABAergic neurotransmission may also be caused by an impaired function of some $\mathrm{GABA}_{\mathrm{A}}$ receptors, e.g. when occupied by antibodies against them, similarly as in myasthenia gravis. It would be interesting to search for antibodies against $\mathrm{GABA}_{\mathrm{A}}$ receptors in OMS patients. Another possible approach is to stimulate postsynaptic $\mathrm{GABA}_{\mathrm{A}}$ receptors with an analog of GABA - gabapentinum, which has already helped to resolve OMS [12]. We cannot confirm this observation since the second patient did not respond to it. Different subtypes of $\mathrm{GABA}_{\mathrm{A}}$ with several different forms of the subunits may explain the heterogenous responses to various drugs. In the future, it is worth trying to achieve a higher concentration of GABA in the synaptic cleft by inhibiting GABA transaminase with gabitril. We propose that clonazepam high doses may be a beneficial therapeutic option in some patients with opsoclonus and myoclonus.

\section{Acknowledgment}

This paper is a contribution to the research project MSM 0021620816.

\section{References}

1 Pranzatelli MR: The neurobiology of the opsoclonus-myoclonus syndrome. Clin Neuropharmacol 1992;15:186-228.

2 Pranzatelli MR: The immunopharmacology of the opsoclonus-myoclonus syndrome. Clin Neuropharmacol 1996;19:1-47.

3 Glatz K, Meinck HM, Wildemann B: Parainfectious opsoclonus-myoclonus syndrome: high-dose intravenous immunoglobulins are effective. J Neurol Neurosurg Psychiatry 2003;74:279-280. 
4 Oguro K, Kobayashi J, Aiba H, Hojo H: Opsoclonus-myoclonus syndrome with abnormal single photon emission computed tomography imaging. Pediatr Neurol 1997;16: 334-336.

5 Bartos A, Pitha J: Opsoclonus-myoclonusdysequilibrium syndrome: cytological and immunological dynamics in the serial cerebrospinal fluid in two patients. J Neurol 2003;250:1420-1425.

6 Helmchen C, Rambold H, Sprenger A, Erdmann C, Binkofski F: Cerebellar activation in opsoclonus: an fMRI study. Neurology 2003;61:412-415.
7 Anderson NE, Budde-Steffen C, Rosenblum MK, Graus F, Ford D, Synek BJ, Posner JB: Opsoclonus, myoclonus, ataxia, and encephalopathy in adults with cancer: a distinct paraneoplastic syndrome. Medicine (Baltimore) 1988;67:100-109.

8 Caviness JN, Forsyth PA, Layton DD, McPhee TJ: The movement disorder of adult opsoclonus. Mov Disord 1995;10:22-27.

9 Straube A, Leigh RJ, Bronstein A, Heide W, Riordan-Eva P, Tijssen CC, Dehaene I, Straumann D: EFNS task force - therapy of nystagmus and oscillopsia. Eur J Neurol 2004; 11:83-89.
10 Klempir J, Vymetalova P, Ulmanova L, Roth J: Syndrom opsoklonus-myoklonus: přehled a kazuistika [Opsoclonus-myoclonus syndrome: a review and a case report]. Ces A Slov Neurol Neurochir 2004;67/100:137140.

11 Tanaka C, Bowery NG: GABA: Receptors, Transporters and Metabolism. Basel, Birkhäuser, 1996.

12 Moretti R, Torre P, Antonello RM, Nasuelli D, Cazzato G: Opsoclonus-myoclonus syndrome: gabapentin as a new therapeutic proposal. Eur J Neurol 2000;7:455-456. 